\title{
Review blames BSE outbreak on calf feed
}

\section{David Adam, London}

Researchers studying the early days of the bovine spongiform encephalopathy (BSE) epidemic may have solved the mystery of why the disease developed in Britain, and why it emerged in the 1980s.

A review of the origins of BSE released on 19 July reveals that British farmers changed the diets of young calves to routinely include meat and bone meal (MBM) in the 1970s.

BSE is known to have been spread by contaminated MBM. The mixture has been regularly fed to older cattle around the world since the 1950s; feeding it to calves seems to have occurred in Britain, but not in the rest of Europe or the United States.

The review modifies the conclusions of last year's BSE inquiry, which suggested that the disease may have been caused by a freak genetic mutation.

The new review's finding suggests that young calves may be more susceptible than older cows to BSE. Epidemiologists studying the disease already suspected this, with some saying the risk to calves is 30 times higher. The new review recommends that possible age-related susceptibility should be tested.

Last year's inquiry, chaired by the judge Lord Phillips (see Nature 408, 3-6; 2000), failed to pick up the fact that feeding MBM to calves was largely restricted to Britain. "There was no attempt to conceal anything, it's just that the right questions never came up," says animal-feed consultant Brian Cooke, formerly of feed supplier Dalgety Agriculture, who presented evidence to the inquiry.

As a result, the finding has surprised many researchers. "I had not been aware that this was a practice introduced in the UK but had not been introduced elsewhere," says Peter Smith, an epidemiologist at the London School of Hygiene and Tropical Medicine and acting chairman of the government's Spongiform Encephalopathy Advisory Committee (SEAC).

Smith says that age-related susceptibility to BSE "must be a tenable hypothesis". He adds that parallels can be drawn to the emergence of the human equivalent of BSE, variant Creutzfeldt-Jakob disease (vCJD), which seems to affect mainly young people.

Smith does not think that this is because younger people are likely to have eaten more cheap pies and hamburgers - which are more likely to have contained potentially infectious brain and spinal cord. "I find it hard to get to grips with the idea that the age distribution in people is purely down to exposure," he says.

Why BSE should emerge in Britain alone when cows across the world had been eating MBM for decades puzzles researchers. Some say the disease originated from cows eating MBM prepared from sheep with a related

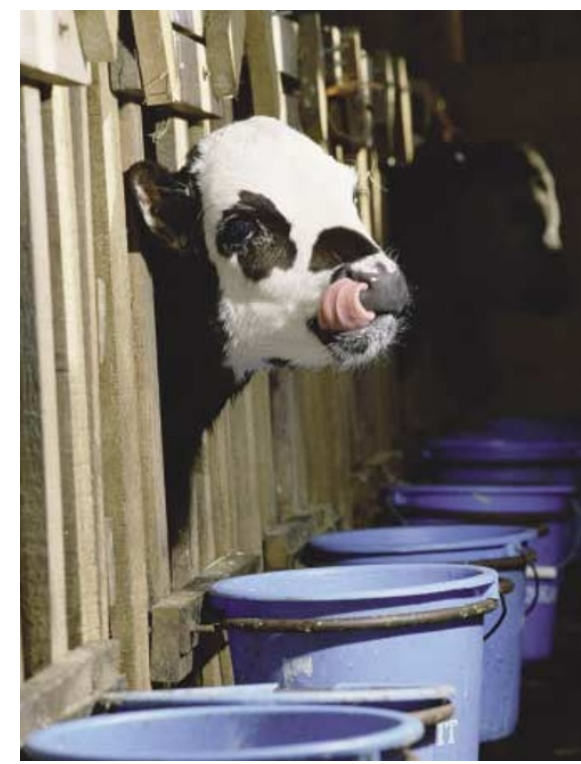

Feeding time: scrapie-infected meat and bone meal may have been fed to young calves.

encephalopathy called scrapie. Others argue that scrapie is so widespread it is inconceivable that such a jump would only happen in one place at one time, and so favour the 'freak genetic mutation' hypothesis.
This was the explanation favoured by the Phillips inquiry, which ruled out scrapie as the source. Many researchers felt this conclusion went beyond the available evidence. The new review was commissioned by the government to clear up this point, and concludes that scrapie cannot be excluded.

BSE is different from known strains of scrapie. But it might have been transformed in passing from sheep to cattle, or have been a rare strain that escaped researchers' notice.

"If you consider the properties of scrapie and the limited studies of the scrapie agent, one cannot rule out the unmodified scrapie agent in the way that Phillips did," says Gabriel Horn, professor of zoology at the University of Cambridge, who led the review committee.

One piece of evidence that implicates scrapie is that the only other country known to have introduced home-produced MBM to calf feed in the 1970s was Australia, which is free of scrapie - and of BSE.

But others are not convinced. "It would surprise me if MBM in calf feed was the sole reason why the BSE epidemic started in the UK and didn't appear anywhere else," says Malcolm Ferguson-Smith, a veterinary pathologist at Cambridge University and a co-author of the Phillips report.

\section{Pressure grows over US blood ban}

\section{Sally Goodman, Paris}

Blood-bank managers on both sides of the Atlantic are growing alarmed at the impact of proposed US restrictions on the importation of European blood.

The US Food and Drug Administration (FDA) and the American Red Cross are planning the restrictions as a precaution against the possible transmission through the blood supply of variant CreutzfeldtJakob Disease (vCJD), the human form of mad cow disease.

But the public organizations and charities that run the blood banks hope that researchers will quickly establish reliable diagnostic tests for VCJD in blood, so that the restrictions can be lifted.

One victim of the restrictions will be an agreement called Euroblood, under which blood products are exchanged between the United States and some European countries, currently the Netherlands, Germany and Switzerland.

Officials in New York city, which relies on blood imported from Europe for up to a quarter of its total supply, face an acute shortage as the restrictions come into effect. Robert Jones, president of the New York Blood Center, warns that the ban on
European blood would cause a medical crisis in the city. "We need to look at the relative risks here and balance these with the known risks of reduced blood supply," he says.

European officials say the restrictions are unnecessary and will undermine public confidence in the blood supply.

But reports that the restrictions will damage the European pharmaceutical industry by reducing supplies of blood plasma obtained from the United States under Euroblood are untrue, industry officials say, as the industry now imports plasma privately.

The FDA plans to implement the ban next year as part of broader guidelines to protect the US blood supply from vCJD that were proposed by an advisory committee last month (see Nature 412, 7; 2001).

The American Red Cross, which collects half of the US blood supply, is planning to exclude donors who have spent over six months in Europe since 1980, or three months in Britain. "We believe this will be an interim action, hopefully soon eclipsed by scientific information," says Bernadine Healy, president of the organization. "When we have a blood test it may be appropriate to modify this geographic deferral." 